\title{
Comprehensive Survey on Internet of Things (IoT)
}

\author{
Ms. Komal.S.Patil ${ }^{1}$, Prof. Jayashri Patil ${ }^{2}$ \\ ${ }^{1} P G$ Student, Godavari College of Engineering, Jalgaon, Maharashtra, India \\ ${ }^{2}$ Assistant Professor, Godavari College of Engineering, Jalgaon, Maharashtra, India
}

\begin{abstract}
The world with full of devices sensor and other objects which will communicate and make human life far better and easier than ever. Internet of things (IoT) is expected to have a massive impact on consumer product. Internet of Things (IOT) refers to physical and virtual objects that have unique identities and are connected to the internet to facilities intelligent applications that make energy, logistics, industrial control, retail, agriculture and many other domains "smarter". Internet of Things is a new revolution of the internet that is rapidly gathering momentum driven by the advancements in sensor networks, mobile devices, wireless communication, networking and cloud technologies. In this paper provides the current research work on IOT term.
\end{abstract}

Keywords - Internet of Things.

\section{I -INTRODUCTION}

I nternet of Things (IoT) comprise things that have unique identities and are connected to the Internet. While many existing devices, such as networked computers or $4 \mathrm{G}$ - enabled mobile phones, already have some form of unique identities and are also connected to the Internet, the focus on IoT is in the configuration, control and networking via the Internet of devices or "things" that are traditionally not associated with the internet. The Internet of Thiongs (IoT) is an emerging paradigam that enables the communication between electronic devices and sensor through the internet in order to facilities our lives. IoT use smart devices and internet to provide innovative solutions to various challenges and issue releated to various business, governmental and public/private industries across the world. IoT has also shown its importance and potential in the economic and industrial grwth of a developing region. A great transformation can be observed in our daily routine life along with the increasing involvement of IoT devices and technology. One such development of IoT is the concept of smart Home System (SHS) and appliances that consists of internet based devices, automation system for home and reliable management system.

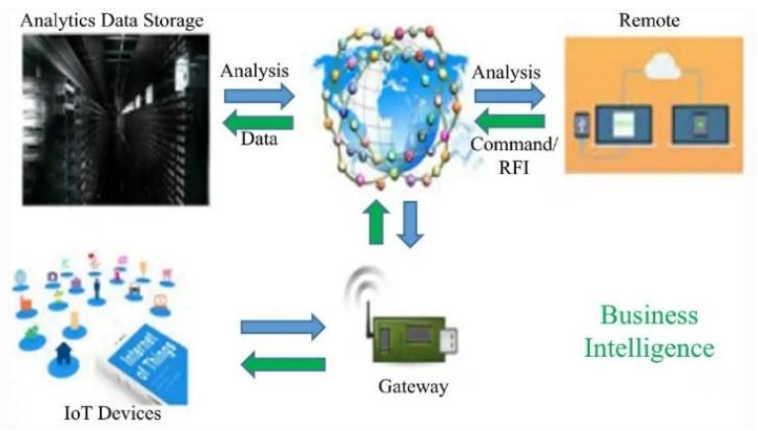

Fig1-General Architecture of IOT 


\section{International Journal of Innovations in Engineering and Science, www.ijies.net}

\section{II -LITETATURE REVIEW}

IoT has multidisciplinary vision to provide its benefits to several domain such as medical, industrial. fig 2 show the few application domains of IoT potentials. Different researchers have explained the IoT differently with respect to specific interest and aspect.

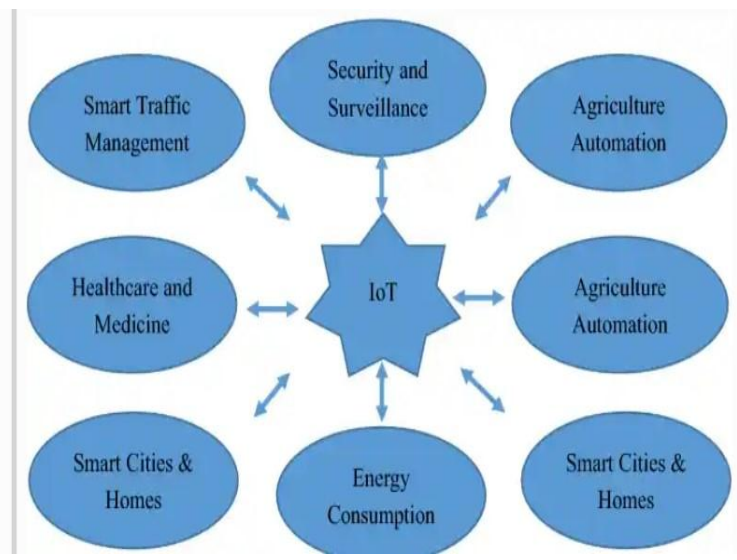

Fig2-Some of the potential application domains of IOT

\section{III -METHODOLOGY}

IoT Architecture and Technology-The IoT architecture consists of five important layers that defines all the functionalities of IoT systems. These layers are perception layer, network layer, middleware layer, application layer, business layer. This transmission of information may use any wired/wireless medium along with $3 \mathrm{G} / 4 \mathrm{G}$, Wi-Fi, Bluetooth etc. Next level layer is known as middleware layer. The main task of this layer is to process the information received from the network layer and make decisions based on the results achieved from ubiquitous computing. Next, this processed information is used by application layer for global device management. On the top of the architecture, there is a business layer which control the overall IoT system, its applications and services. Figure 3 illustrates such functional blocks of IoT architecture.

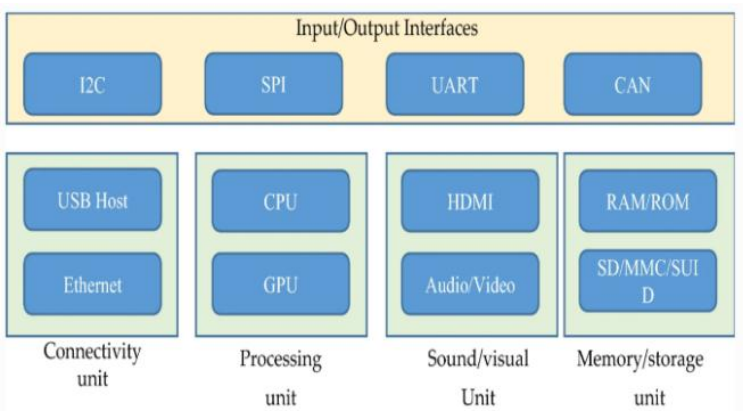

Fig3 -A generic module function of IOT standard architecture that is suitable for global IoT [39]. Therefore, a suitable architecture is still needsvk to be designed that could satisfy the global IoT needs. The generic working structure of IoT system is shown in . Figure 4 shows a dependency of IoT on particular application parameters. IoT gateways have an important role in IoT communication as it allows connectivity between IoT servers and IoT devices related to several applications.

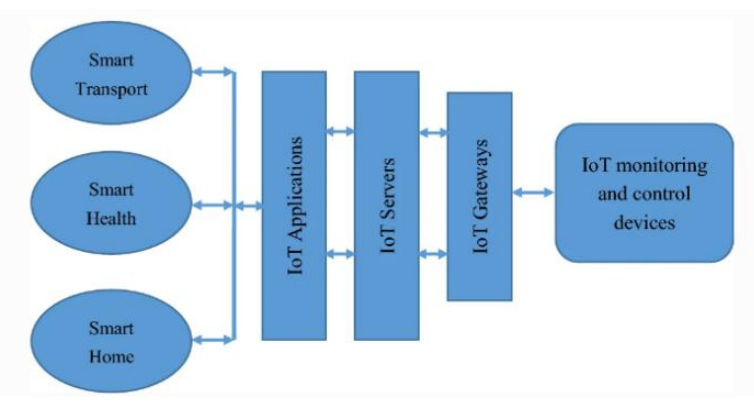

Fig 4-Working Structure of IOT

\section{IV -MAJOR IOT APPLICATION}

Emerging economy, environmental and health-care

IoT is completely devoted to provide emerging public and financial benefits and development to the society and people. This includes a wide range of public facilities i.e. economic development, water quality maintenance, well-being, industrialization etc. Overall, IoT is working hard to accomplish the social, health and economic goals of United Nations advancement step. Environmental sustainability is another important concern. IoT developers must be concerned about environmental impact of the IoT systems and devices to overcome the negative impact . Energy consumption by IoT devices is one of the challenges related to environmental impact

\section{Smart city, transport and vehicles}

IoT is transforming the traditional civil structure of the society into high tech structure with the concept of smart city, smart home and smart vehicles and transport. Rapid improvements are being done with the help of supporting technologies such as machine learning, natural language processing to understand the need and use of technology at home Various technologies such as cloud server technology, wireless sensor networks that must be used with IoT servers to provide an efficient smart city. Another important issue is to think about environmental aspect of smart city. 


\section{International Journal of Innovations in Engineering and Science, www.ijies.net}

\section{Agriculture and industry automation}

The world's growing population is estimated to reach approximate 10 billion by 2050. Agriculture plays an important role in our lives. In order to feed such a massive population, we need to advance the current agriculture approaches. Therefore, there is a need to combine agriculture with technology so that the production can be improved in an efficient way.
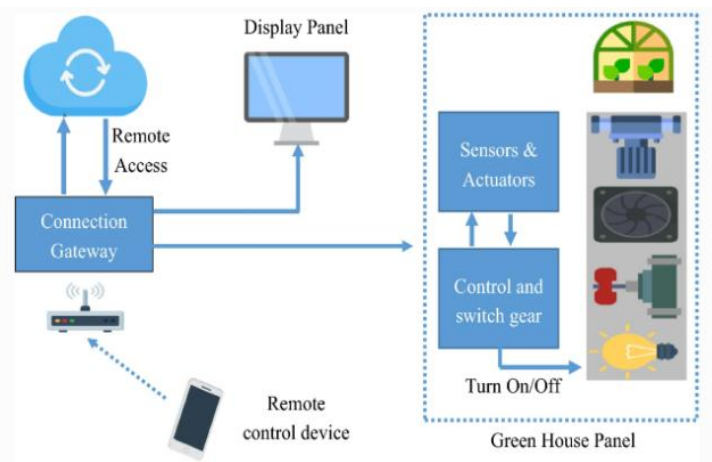

Fig 5- A working structure of IOT system in agriculture production

\section{V -IMPORTANCEOF BIG DATA ANALYSTIC IN IOT}

An IoT system comprises of a huge number of devices and sensors that communicates with each other. With the extensive growth and expansion of IoT network, the number of these sensors and devices are increasing rapidly. These devices communicate with each other and transfer a massive amount of data over internet. This data is very huge and streaming every second and thus qualified to be called as big data. The real time traffic information can be collected through IoT devices and sensors installed in traffic signals and this information can be analyzed in an IoT based traffic management system. In healthcare analysis, the IoT sensors used with patients generate a lot of information about the health condition of patients every second. This large amount of information needs to be integrated at one database and must be processed in real time to take quick decision with high accuracy and big data technology is the best solution for this job. IoT along with big data analytics can also help to transform the traditional approaches used in manufacturing industries into the modern one [63]. The sensing devices generates information which can be analyzed using big data approaches and may help in various decision making tasks. Furthermore, use of cloud computing and analytics can benefit the energy development and conservation with reduced cost and customer satisfaction.

\section{VI -CONCLUSION}

Recent advancements in IoT have drawn attention of researchers and developers worldwide. IoT developers and researchers are working together to extend the technology on large scale and to benefit the society to the highest possible level. However, improvements are possible only if we consider the various issues and shortcomings in the present technical approaches. In this survey article, we presented several issues and challenges that IoT developer must take into account to develop an improved model. The digital era revolutionized human society during the last century. In fact, information digitization processes have led to the design of computers, phones and other machines offering a plethora of applications running on standalone computing machines. Then digitized information transport developed. This has introduced digital communication and networking where machines are connected to form very large networks and offer remote applications. These machines connected to these networks created the opportunity to deploy different services, either in voice communication, data transfer or entertainment, such as TV, and has led to this digital society. Our society is now totally dependent on the biggest ever network, the Internet; one of the major and most astonishing of human inventions. In this network, most of the information traffic is created and generated by people through email, the web and other user services.

\section{REFERENCE}

[1] Sfar AR, Zied C, Challal Y. A systematic and cognitive vision for IoT security: a case study of military live simulation and security challenges. In: Proc. 2017 international conference on smart, monitored and controlled cities (SM2C), Sfax, Tunisia, 17-19 Feb. 2017.

[2] Sfar AR, Natalizio E, Challal Y, Chtourou Z. A roadmap for security challenges in the internet of things. Digit Commun Netw. 2018.

[3] Z. Alansari, N. B. Anuar, A. Kamsin, M. R. Belgaum, J. Alshaer, S. Soomro, and M. H. Miraz, "Internet of Things: Infrastructure, Architecture, Security and Privacy", in 2018 International Conference on Computing, Electronics Communications Engineering (iCCECE), pp. 150- 155, Aug 2018, DOI: 10.1109/iCCECOME.2018.8658516. 
Vol. 6, No. 10, 2021, PP. 213 -216

\section{International Journal of Innovations in Engineering and Science, www.ijies.net}

[4] J. A. Chaudhry, K. Saleem, P. S. Haskell-Dowland, and M. H. Miraz, "A Survey of Distributed Certificate Authorities in MANETs," Annals of Emerging Technologies in Computing (AETiC), vol. 2, no. 3, pp. 11- 18, 2018, DOI: 10.33166/AETiC.2018.03.002. [17]

[5] A. S. A. Daia, R. A. Ramadan, and M. B. Fayek, "Sensor Networks Attacks Classifications and Mitigation", Annals of Emerging Technologies in Computing (AETiC), vol. 2, no. 4, pp. 28-43, 2018, DOI: 10.33166/AETiC.2018.04.003.

[6] Cooper and A. James, "Challenges for database management in the internet of things" IETE Technical Review,vol.26,no.5,pp.320-329,2009.

[7] D. B. Ansari, A.-U. Rehman, and R. Ali, "Internet of Things (IoT) Proto- cols: A Brief Exploration of MQTT and CoAP," International Journal of Computer Applications, vol. 179, pp. 9-14, 032018. 